\title{
RELATION OF BLOOD-BORNE AGENTS ACTING ON MESEN- TERIC VASCULAR BED TO GENERAL CIRCULATORY REACTIONS ${ }^{1}$
}

\author{
BY BENJAMIN W. ZWEIFACH AND DELILAH B. METZ
}

(From the Department of Biology, New York University, N. Y.)

(Submitted for publication September 27, 1954 ; accepted December 22, 1954)

An intensive study of the behavior of the mesenteric circulation in relation to previously undescribed humoral substances has provided a unique challenge to our physiological concepts of peripheral vascular homeostasis. The regular appearance of the vasoactive principles VEM and VDM in the blood during particular phases of shock and hypertension, coincident with an impairment of specific inactivating systems for these substances within the kidney and liver, have been suggested $(1,2)$ as critical factors underlying the progressive derangement of the systemic circulation in these conditions. As a basic concept, it was proposed that the hepatorenal factors, VEM and VDM, represent constituents of a general homeostatic mechanism essential for effective regulation of blood flow within the tissue proper (2).

The implied relationship of these principles to systemic phenomena, such as blood pressure, compensatory vasoconstriction, and overall vascular reactivity, has been contested in view of the failure of different investigators to influence these processes, either by the acute and chronic administration of ferritin-"VDM" (3-5), or by surgical extirpation of the kidneys $(6,7)$. In the case of human bioassay data $(8,9)$, the question has been raised whether we are dealing with biochemical processes, causally related to concurrent circulatory disturbances, or with a relationship secondary to local vascular changes developing in different organs out of an imbalance in the systemic circulation.

The current report represents an experimental appraisal of the proposed physiological implica-

1 This investigation was supported in part by a research grant (H-1244) from the National Heart Institute, of the National Institutes of Health, United States Public Health Service, and a grant from the Life Insurance Medical Research Fund. tions of blood-borne agents identified by the rat mesoappendix procedure. Special consideration was given to VEM and VDM in relation to particular systemic functions, such as blood pressure, vasoconstriction, vasodilation, and the development of abnormal circulatory conditions.

\section{MATERIALS AND METHODS}

The rat mesoappendix bioassay is based upon the detection of alterations in the constrictor response of the arteriolar elements of the terminal vascular bed to topically applied epinephrine following the intravenous administration of aliquots of blood or tissue extracts. Details of the method and its biological implications have been published elsewhere $(10,11)$. The least concentration of epinephrine, sufficient to produce contraction of the precapillaries and to bring to a halt the blood flow in the capillary bed proper, is referred to as the threshold concentration (E.T.C.). The intravenous administration of biologically active agents shifts the response to epinephrine, either in the direction of increased reactivity or potentiation $(\mathrm{eP})$, or causes the vessels to become refractory to epinephrine, an inhibitory (eI) reaction. Shifts in vascular reactivity are estimated by comparing the concentration of epinephrine required to elicit the threshold response at the newly established level with that of the control E.T.C. value. In addition, a record is made of the period of time during which the reaction change persisted in the test rat. The bioassay has been shown to be sufficiently accurate to permit identification of exceptionally low concentrations of eI or eP substances in biological specimens under different experimental conditions (12). The quantitative implications of the method have, however, been found to be limited.

In the present investigation, blood samples or other vasoactive materials were introduced for bioassay in doses of $0.5 \mathrm{ml}$. per $150 \mathrm{gm}$. rat. The crystalline ferritin used was prepared from horse spleen and purified according to the method of Mazur and Shorr (13). Renal VEM was prepared by incubating fresh slices of rat kidney for 45 minutes under anaerobic conditions at $37.5^{\circ} \mathrm{C}$. in the Warburg bath, using a proportion of 1 gram of tissue to 5 parts of Ringer-phosphate solution. 


\section{EXPERIMENTAL FINDINGS}

\section{A. Independence of blood-borne vasoactivity and systemic blood pressure}

Two sets of experiments were conducted in order to determine whether eI and eP substances bear more than a temporal relation to fluctuations in the systemic blood pressure; in one, the question was explored as to the extent to which the local constrictor reaction to epinephrine was influenced by agents which elevate or lower blood pressure; and in the second, the reverse situation was ex- amined, the effect of humorally mediated $\mathrm{eP}$ or eI reactions on the blood pressure level.

1. Pressor-depressor agents: In the initial studies, equivalent hyper- and hypotensive excursions were instituted acutely by a series of pressor or depressor agents in rats in which the cecal mesentery had been exposed for microscopic examination. The findings summarized in graph form in Figure 1 represent average values established for each substance in four animals. It is clearly evident that all variants of the several possibilities in such an experiment were encountered. Al-

eP and eI Activity in Relation to Blood Pressure

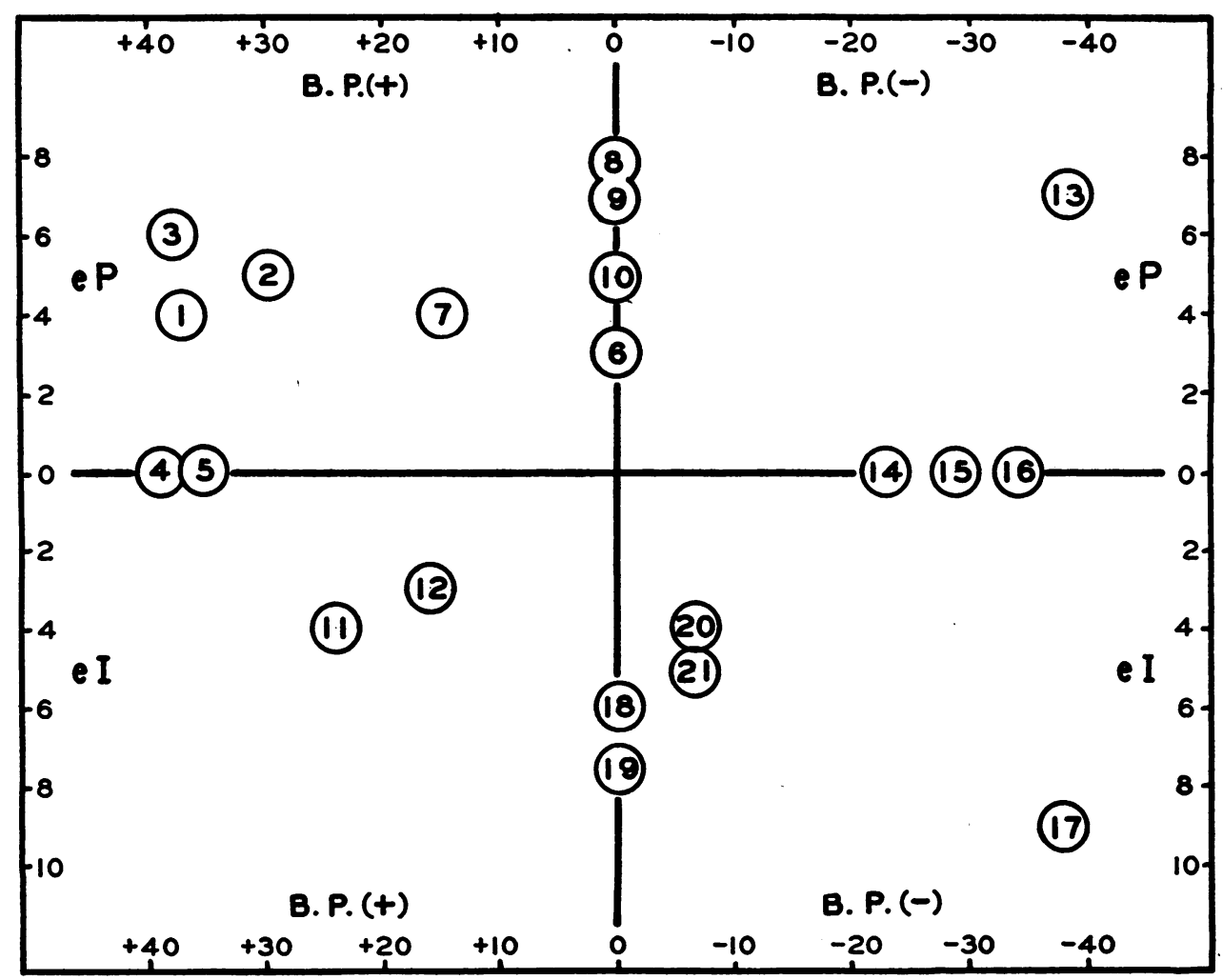

Fig. 1. Scatter Plot Indicating eP or el Activity in Relation to the Blood Pressure Change Efrected by Different Agents

Hyper- or hypotensive action does not bear an obligatory relationship to the reactivity of the muscular vessels, as measured by the constrictor response to topical epinephrine. $\mathrm{eP}$ and eI activity expressed as multiples of the control E.T.C. values along ordinate axis, and B.P. change by values above $(+)$ or below $(-)$ control level along abscissa. (1) renin, 1 p.u., (2) angiotonin, 1.5 p.u., (3) 1-arterenol, $2.5 \mu \mathrm{g} .$, (4) barium chloride, $0.1 \mathrm{mg} .,(5)$ Neo-Synephrine(6), 0.25 mg., (6) Pitressin .001 p.u., (7) Pitressin', 01 p.u., (8) kidney VEM, 0.5 ml., (9) $\mathrm{KCl}, 5 \mathrm{mg}$., (10) adenylic acid, $0.3 \mathrm{mg} .$, (11) serotonin, $0.2 \mathrm{mg} .,(12)$ Paredrine $0,0.5 \mathrm{mg}$., (13) histamine, $0.25 \mathrm{mg}$., (14) Priscoline $0.2 \mathrm{mg}$., (15) sodium nitrite, $0.1 \mathrm{mg}$., (16) Benodaine(

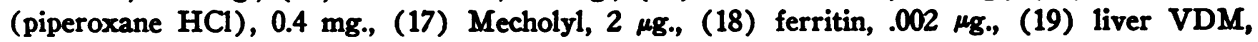
$0.5 \mathrm{ml}$., (20) glutathione (GSH), $.05 \mu \mathrm{g} .,(21)$ cystein, $0.2 \mathrm{mg}$. The plotted data are average values of four rats for each substance. 
though the particular pressor agents (renin, angiotonin, 1-arterenol, Pitressin( $\left.{ }^{(}\right)$had a measurable effect on the local reactivity of the terminal vascular bed, others such as barium chloride or NeoSynephrine did not alter vascular reactivity in the mesenteric vessels at concentrations which produced an equivalent elevation of blood pressure. As indicated, still another group of hypertensive substances (serotonin, Paredrine ${ }^{\circledR}$ ) depressed vascular reactivity. An eP reaction was also elicited by agents which had no measurable effect on the systemic blood pressure.

The majority of the hypertensive agents exhibited a progressively greater eP effect with higher doses, until a maximally effective concentration was reached. In the case of Pitressin ${ }^{(1)}$ epinephrine potentiating effects (three to five times) were encountered with doses (.001 to .01 p.u.) well below the range influencing the arterial pressure. With pressor concentrations (10 p.u., +20 to $25 \mathrm{~mm}$. $\mathrm{Hg}$ ), the resulting eP change was of the same magnitude (four to five times), but persisted for much longer periods. On the other hand, serotonin at pressor concentrations ( 0.1 to $0.2 \mu \mathrm{g}$.) tended to depress vascular reactivity in five out of six animals, as indicated by an eI effect in the mesentery, while at sub-pressor concentrations (.05 to $.01 \mathrm{\mu g}$. in five animals) it rendered the precapillaries hyperreactive to local epinephrine.

The scatter plot indicates that the depressant action of agents on the blood pressure was likewise independent of their vasoactive potentialities in the mesentery. In contrast to the eI influence of certain hypotensive materials (See Figure 1), Priscoline, sodium nitrite, or Benodaine (piperoxane $\mathrm{HCl}$ ) in doses which elicited an equivalent fall in blood pressure, did not change the reaction to topical epinephrine.

2. Failure to predispose to acute pressor effect of i.v. epinephrine: Shifts in vascular reactivity in the mesentery should be reflected in an altered general response to vasomotor stimuli, provided that these agents have a comparable action in other areas. The influence of eP or eI substances on the acute pressor response to the intravenous injection of epinephrine was explored in 12 experiments where both blood pressure and microscopic observations in the mesentery were carried out. Intravenous injections were made of $\mathrm{eP}$ or $\mathrm{eI} \mathrm{ma-}$ terials-crystalline (angiotonin, ferritin), tissue extracts (kidney VEM and liver VDM), and blood specimens (human plasma). When the vascular bed in the mesentery showed maximal displacement of the E.T.C., a standard intravenous dose of epinephrine ( $2 \mu \mathrm{g}$. per $100 \mathrm{gm}$. body weight) was administered. In the above 12 animals, no consistent predisposing influence was noted on the magnitude or duration of the hypertensive response as compared with the control reaction.

In experimental shock, Page (14) has shown that the overall vascular reactivity, as determined by the systemic pressor response to a series of test agents, was depressed during the terminal stages of the shock syndrome. This stage corresponds with the period during which our observations (15) indicated hyporeactivity to topical epinephrine in the mesoappendix and omentum of shocked animals. The two independent sets of observations suggested that the hyporeactive behavior of the vessels to systemic and to local influences might be a reflection of the same vascular defect. The vasoconstrictor drugs tested systemically by Page during shock in dogs were applied topically to the surface of the mesentery in four rats subjected to hemorrhagic shock ( 1 hour at $50 \mathrm{~mm}$. $\mathrm{Hg}$ followed by 2 hours at $35 \mathrm{~mm}$. $\mathrm{Hg}$ ). Although the vessels showed an eI reaction, they were not refractory to topically applied angiotonin or Pitressine.

\section{B. Continuous intravenous infusion of $e P$ and $e I$ agents}

The preceding experiments deal exclusively with acute injections of humoral agents and may not provide a sufficiently sustained action of these materials to influence the systemic blood pressure. Continuous delivery of VDM and VEM into the bloodstream was therefore instituted for periods of from 45 to 120 minutes. This was accomplished in the rat by means of a motor-driven ultra-microburette which permitted accurate delivery of a total volume of .003 to $.03 \mathrm{ml}$. per minute. Such small volumes obviated any possible alterations in blood volume during the experimental period. The infusions were made either intravenously or directly into the descending arch of the aorta through an indwelling plastic catheter in the left common 
Continuous Infusion of Ferritin

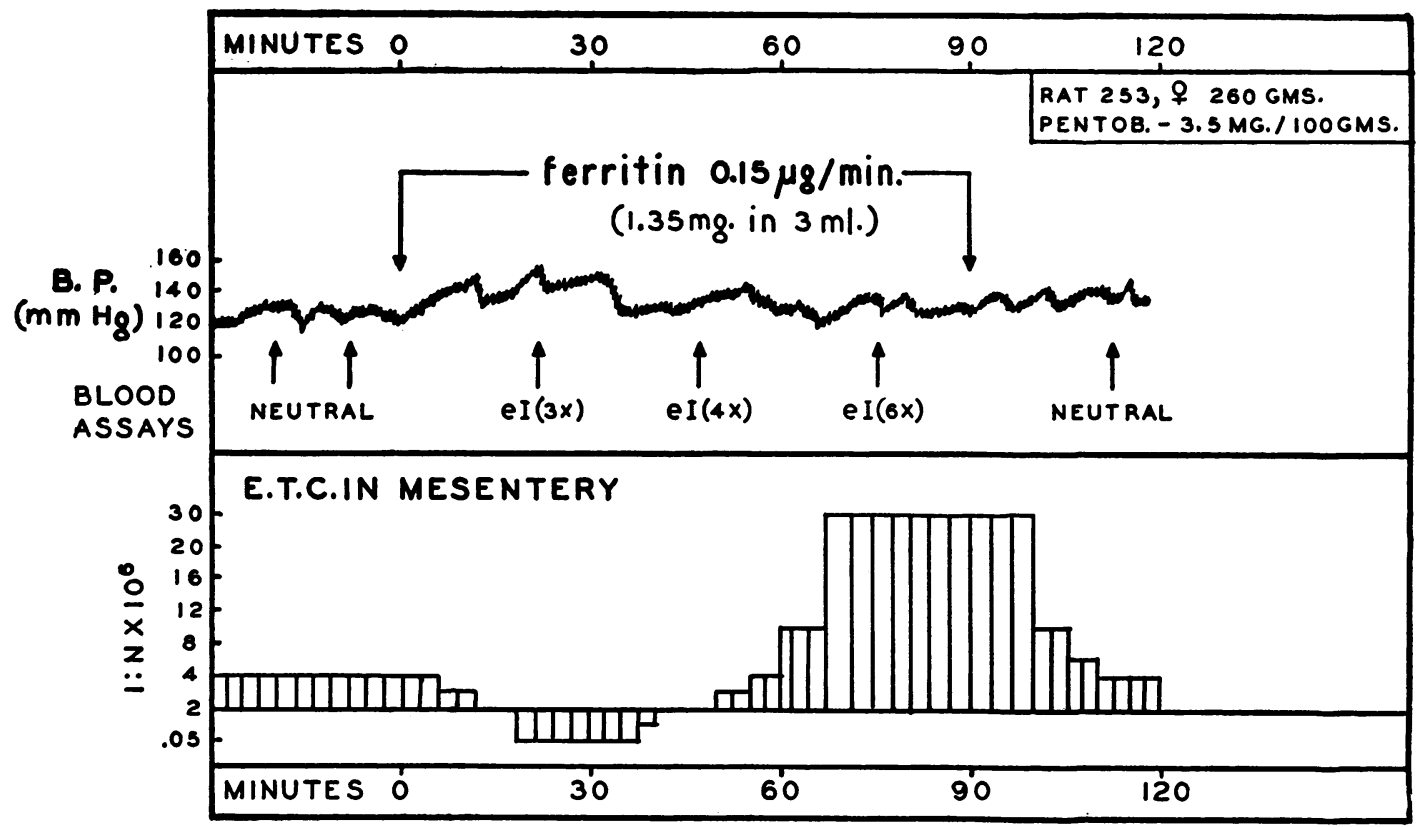

Continuous Infusion of VEM

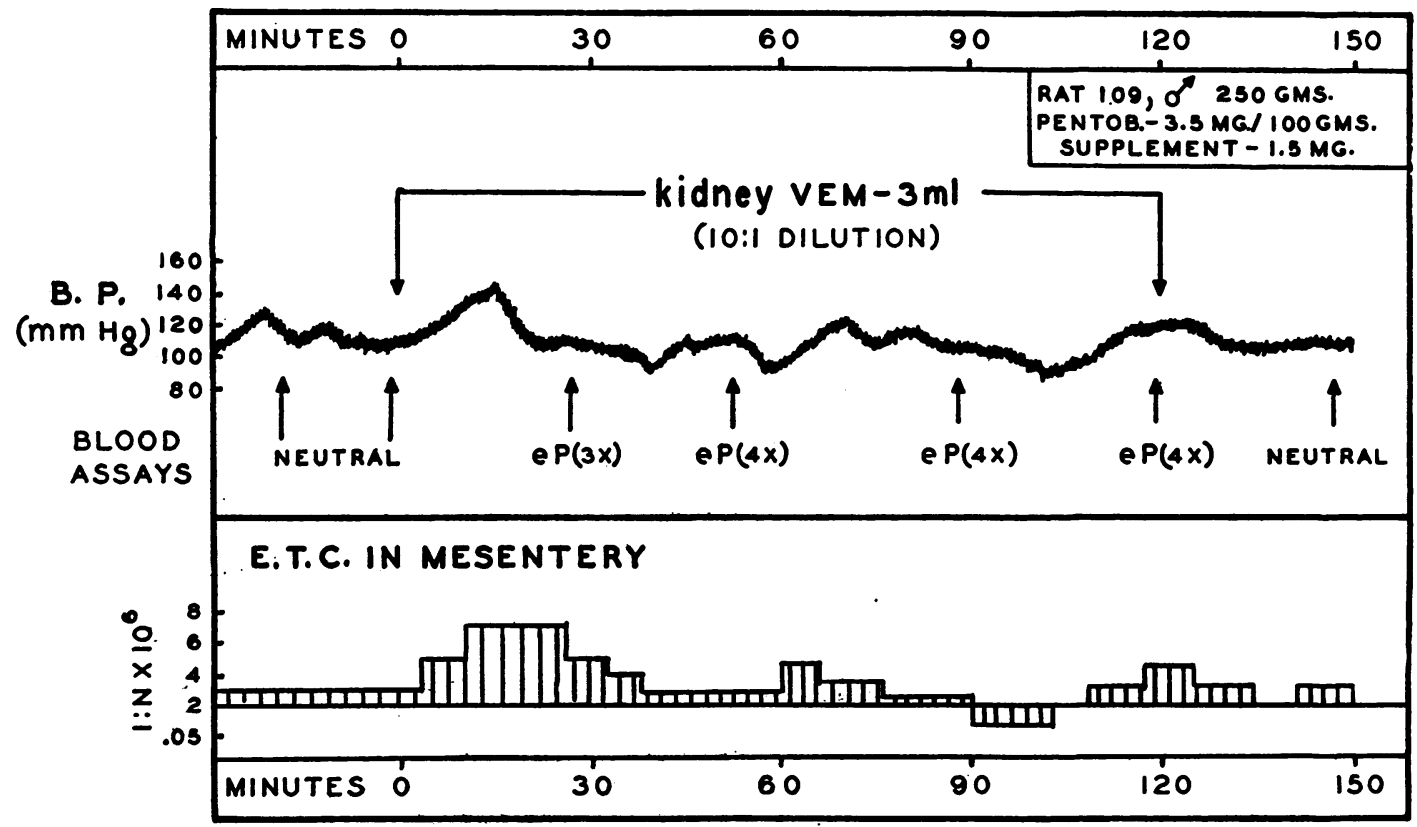

Fig. 2. Administration of el Agent (Ferritin) and eP Agent (Rat Kmney Vem-Anaerobic Incubation of Fresh Kidney Slices for 60 Min. in Ringer-Phosphate, $5: 1$ ) via Catheter in Femoral Vein by MOtor Driven Ultra-MicroburetTe

Blood pressure recorded at $3 \mathrm{~min}$. intervals by mercury manometer in carotid artery, vascular reactivity topically in mesoappendix, and heparinized blood specimens $(0.2 \mathrm{ml}$.) removed for bioassay as indicated. 
carotid artery. Parallel measurements were made of arterial blood pressure and vascular reactivity in the mesentery.

In a series of 10 animals, ferritin (in a range of from 0.1 to $.001 \mu \mathrm{g}$. per ml. at a rate of $1 \mathrm{ml}$. per hour) had no significant effect on blood pressure. A representative protocol of this group is shown in Figure 2a. Continuous infusion for two hours of VDM, prepared by in vitro anaerobic incubation of liver tissue, likewise did not alter the blood pressure. Blood samples, removed at intervals for bioassay throughout these experiments, showed positive titers of vasoactivity, indicating that effective blood levels had been maintained by the infusion procedure.

Similar infusion experiments with renal VEM in six animals showed no pressor action (Figure 2b). Negative effects on blood pressure were also obtained with infusions of VEM and VDM in three animals which had been nephrectomized, and in four eviscerated rats (liver and gastrointestinal tract removed according to procedure of Engel, Harrison, and Long [16]). This procedure ruled out the influence of the kidney and liver in suppressing any possible systemic action of the eP and eI agents.

Direct microscopic visualization was also carried out to ascertain whether the prolonged administration of an eI substance, ferritin, would continue to depress the constrictor response to epinephrine throughout the period of infusion. In eight experiments of this type, a wide range of concentrations (.001 to $.25 \mu \mathrm{g}$. per ml.) were used, including doses which in single injections in assay experiments uniformly elicited an eI reaction. Despite the infusion of ferritin for periods up to 120 minutes, it was not possible to maintain the vascular response to epinephrine at hyporeactive levels by this means for more than 20 to $25 \mathrm{~min}$ utes. In the infusion experiment illustrated in Figure 2a, a concentration of ferritin of $.015 \mu \mathrm{g}$. per $\mathrm{ml}$. elicited an initial short period of hyporeactivity, which was followed by a prominent phase of hyperreactivity until, at the end of 30 to 40 minutes, the E.T.C. in the mesentery had increased from $1: 2$ million to $1: 30$ million. The biphasic pattern of response with ferritin was obtained both with the intravenous and intra-arterial routes of administration. Such infusions resulted in augmented responses not only in the capillary bed proper, but in five of the eight animals caused a hyperreactive condition in the large vessels up to and including small arteries (100 to 200 micra in diameter) and muscular venules (150 to 250 micra in diameter). This type of response was highly atypical, since in the conventional bioassay experiment the acute administration of vasoactive agents led to changes manifest chiefly in the metarterioles and precapillaries.

Ferritin, in addition to its vasoactive properties, has been reported to stimulate the release of the antidiuretic hormone (A.D.H.) from the pituitary (17). The possibility was investigated that the secondary period of hyperreactivity with protracted administration of ferritin might be related to the release of the A.D.H. which, in turn, increased vascular reactivity. However, opposite types of reactions were obtained when low (.01 $\mu \mathrm{g}$. per ml.) and high (.1 $\mu \mathrm{g}$. per ml.) concentrations of ferritin were infused into acutely nephrectomized and/or adrenalectomized animals, as well as in hypophysectomized rats (a series of three rats was studied in each of these experimental categories).

Continuous administration of kidney VEM, was carried out in six normal rats at three concentration levels-the original incubation supernatant, at half dilution, and at one quarter dilution with saline. A similar pattern of response was observed with each of these concentrations. As in the standard bioassay procedure, an eP change in vascular reactivity developed, which however did not persist and became less evident after 35 to 40 minutes despite continued infusion of VEM for another 60 to 90 minutes (see Figure $2 \mathrm{~b}$ ). No inhibition of the epinephrine response developed. Comparable durations of eP reactivity were obtained in different rats irrespective of whether the VEM was infused for periods of $45,60,90$, or 120 minutes. In each instance, the eP effect persisted for only 30 to 45 minutes.

\section{Relation of $e P$ and eI activity to vasoconstric- tion and vasodilation}

Previous studies have not made it clear whether a shift in an eP direction was invariably associated with a tendency towards vasoconstriction, and a shift in an eI direction with vasodilation. Table I is a compilation of different experimental condi- 
tions in which the E.T.C. and/or the caliber of the mesenteric arterioles $(20$ to $30 \mu)$ were shifted from their control status. Increased vascular reactivity was encountered in the mesentery, irrespective of the presence or type of effect on vascular caliber. A similar lack of association was also encountered between eI reactions and vasodilation. The findings, on the basis of both acutely induced changes as well as those in chronic experimental conditions, indicate clearly that vascular caliber per se was not influenced in a predictable manner by an eP or eI tendency in these vessels.

\section{Non-renal eP systems}

Evidence has been presented (18) that $\mathrm{eP}$ agents, in general, exert their effect indirectly by way of the kidney and that the final common denominator, serving to augment vascular reactivity, was the liberation of renal VEM. These data did not seem to be in accord with our recent findings (19) that a wide spectrum of naturally occurring biological agents have $\mathrm{eP}$ and eI properties indistinguishable from VEM and VDM. Two sets of experiments were therefore carried out with a variety of $\mathrm{eP}$ agents in which the hu- moral influence of the kidney was ruled out either by surgical isolation of this organ, or by suppression through adrenalectomy of the renal capacity to produce VEM.

1. Arenal animals: A total of 16 rats were used in this series. One kidney was removed surgically 7 to 10 days prior to the bioassay procedure. The renal pedicle of the second kidney was carefully exposed and isolated immediately preceding exteriorization of the mesoappendix for microscopic observations. After a control E.T.C. response had been established, a small clip was placed across the renal pedicle which had been infiltrated with a local anesthetic (1 per cent cyclaine). By this procedure the intrarenal circulation could be occluded with a minimum of interference to the surrounding structures, especially branches of the greater splanchnic nerve and the celiac plexus. These precautions were found to be essential, since even the minor traction exerted on the renal pedicle by a small clamp was sufficient to elicit in the absence of local anesthesia a significant episode of vascular hyperreactivity in the mesoappendix lasting for 30 to 40 minutes. In the present experiments, a stable E.T.C. was established in 15 to 20 minutes.

TABLE I

Dissociation between vasotonic tendency and epinephrine reactivity

\begin{tabular}{|c|c|c|c|c|c|}
\hline & \multirow{2}{*}{$\begin{array}{l}\text { No. of } \\
\text { cases }\end{array}$} & \multirow{2}{*}{$\begin{array}{c}\text { Experimental } \\
\text { condition }\end{array}$} & \multirow{2}{*}{$\begin{array}{l}\text { Effects on } \\
\text { arteriolar } \\
\text { caliber }\end{array}$} & \multicolumn{2}{|c|}{ Shift in E.T.C.* } \\
\hline & & & & Type & Range \\
\hline \multicolumn{6}{|l|}{ Constrictors } \\
\hline $\begin{array}{l}\text { Hemorrhage } \\
\text { 1-Arterenol } \\
\text { Dibenzyline } \\
\text { 1-Arterenol } \\
\text { Barium chloride }\end{array}$ & $\begin{array}{r}10 \\
12 \\
3 \\
4 \\
3\end{array}$ & $\begin{array}{c}1.5 \%, 1 \mathrm{hr} . \\
0.25 \mathrm{mg} \text {. (i.v.) } \\
2-5 \mu \mathrm{g}, \text { topical } \\
\text { Infusion, .03 ml./min. } \\
0.1 \mathrm{mg} \text {. (i.v.) }\end{array}$ & $\begin{array}{l}+t+ \\
++ \\
+t \\
++ \\
+t\end{array}$ & $\begin{array}{l}\text { eP } \\
\text { eP } \\
\text { eI } \\
\text { eI } \\
0\end{array}$ & $\begin{array}{c}25-30 x \\
4-6 x \\
5-8 x \\
8-9 x \\
0\end{array}$ \\
\hline \multicolumn{6}{|l|}{ Dilators } \\
\hline $\begin{array}{l}\text { Histamine } \\
\text { Denervation } \dagger \\
\text { Adrenalectomy } \\
\text { Low calorie diet } \\
\text { Mecholyl } \\
\text { Glutathione } \\
\text { Sodium nitrite }\end{array}$ & $\begin{array}{r}8 \\
6 \\
6 \\
5 \\
12 \\
6 \\
3\end{array}$ & $\begin{array}{c}0.25 \mathrm{mg} \text {. (i.v.) } \\
\text { Acute } \\
\text { No therapy, } 4 \text { days } \\
15 \text { days } \\
1 \mathrm{\mu g} \text {. (i.v.) } \\
.02 \mathrm{mg} \text { (i.v.) } \\
0.15 \mathrm{mg} \text { (i.v.) }\end{array}$ & $\begin{array}{c}++ \\
+++ \\
++ \\
+ \\
++ \\
+ \\
++\end{array}$ & $\begin{array}{l}\text { eP } \\
\text { eP } \\
\text { eP } \\
\text { eP } \\
\text { eI } \\
\text { eI } \\
0\end{array}$ & $\begin{array}{c}4-10 x \\
10-15 x \\
10-12 x \\
20-25 x \\
12-15 x \\
3-8 x \\
0\end{array}$ \\
\hline \multicolumn{6}{|l|}{ Caliber unchanged } \\
\hline $\begin{array}{l}\text { ACTH } \\
\text { Cortisone } \\
\text { Ferritin }\end{array}$ & $\begin{array}{r}6 \\
4 \\
12\end{array}$ & 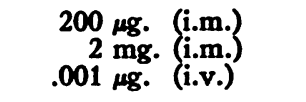 & $\begin{array}{l}\text { None } \\
\text { None } \\
\text { None }\end{array}$ & $\begin{array}{l}\text { eP } \\
\text { eP } \\
\text { eI }\end{array}$ & $\begin{array}{l}3-6 x \\
4-5 x \\
3-5 x\end{array}$ \\
\hline
\end{tabular}

* E.T.C.ex

+ Acute section of greater splanchnic nerve and/or thoraco-lumbar sympathectomy. $\quad+=25$ per cent, $++=50$ per cent, $++t=75$ per cent change in caliber. 
TABLE II

eP reaction of mesenteric vessels in absence of remal VEM

\begin{tabular}{|c|c|c|c|c|}
\hline & $\begin{array}{l}\text { Histamine } \\
(0.25 \text { ms. })\end{array}$ & $\begin{array}{l}\text { Pitressin } \\
(0.1 \text { p.u. })\end{array}$ & $\underset{(1 p \text { penin }}{\text { Ren. }}$ & $\underset{(2.5 \mu 8 .)}{\text { L-arterenol }}$ \\
\hline $\begin{array}{l}\text { Controls* } \\
\text { Arenal* } \\
\text { Adrenalectomy }\end{array}$ & $\begin{array}{l}3 x(35 \text { min. }) \\
4 x(32 \text { min. }) \\
3 x(36 \text { min. })\end{array}$ & $\begin{array}{l}4 x(43 \mathrm{~min} .) \\
3 x(40 \mathrm{~min} .) \\
3 x(41 \mathrm{~min} .)\end{array}$ & $\begin{array}{l}4 x(40 \mathrm{~min} .) \\
5 x(38 \mathrm{~min} .) \\
6 x(46 \mathrm{~min} .)\end{array}$ & $\begin{array}{l}5 x(26 \min .) \\
5 x(32 \mathrm{~min} .) \\
4 x(28 \mathrm{~min} .)\end{array}$ \\
\hline
\end{tabular}

* Average of four experiments in each category listed.

The findings listed in Table II indicated that intravenous injection of potentiating substances elicited in the arenal rats a well-defined potentiation of the response to epinephrine identical with that of control animals.

2. Adrenalectomy: Further evidence in this regard was provided by bioassay experiments on 16 adrenalectomized rats maintained for two weeks on salt ( 1 per cent $\mathrm{NaCl}$ in drinking water) with no hormonal supplementation. Such rats remained in excellent health for several months or longer on this regime. Earlier studies (20) had indicated that the kidneys of the adrenalectomized saltmaintained animals had lost the capacity to produce vasoexcitor material, as demonstrated by in vitro incubation under anaerobic conditions. The response of the mesenteric vascular bed of such animals to vasoactive agents is compared with that of normal controls in Table II. Typical eP reactions were obtained in the mesoappendix of the adrenalectomized salt sustained rat following the intravenous injection of 1 -arterenol, renin, angiotonin, histamine, and Pitressin ${ }^{\otimes}$. This indicated that the $\mathrm{eP}$ effect of these agents could not be attributed to the secondary release of renal VEM, since in vitro examination confirmed the fact that the kidneys of these test animals no longer formed a vasoexcitor principle under anaerobic exposure for 30 to 90 minutes.

One further experimental finding should be cited in this regard. Akers, Hershey, and Zweifach (21) have shown that direct stimulation of the distal end of the greater splanchnic nerve produced comparable eP effects (thirty to eighty times) in the mesentery of both normal and arenal animals. In six such studies, bioassays were carried out on the blood of animals following nerve stimulation. Both normal and arenal rats were used for testing purposes. In each of the twelve samples tested, eP activity, obviously of nonrenal origin, was demonstrated.

\section{E. Blood-borne principles in abnormal blood pres- sure states}

A convincing array of evidence $(2,22)$ exists to support a causal relationship between the humoral principles, renal VEM and hepatic VDM, and various vascular conditions in shock and hypertension. It is the purpose of this section to present recent experimental material which is not in complete accord with the all-inclusive character of some of the earlier interpretations.

1. Hypertension: The precise relationship of eI and $\mathrm{eP}$ materials in the blood of patients suffering from various diseases, including hypertension and congestive heart failure, to the derangement of blood pressure in these states, remains problematical. In order to clarify this issue, the rat mesoappendix method was used to indicate the presence or absence of vasoactive materials in blood samples from clinic patients ${ }^{2}$ selected at random. Blood specimens were collected under controlled conditions, from patients receiving no medication for 24 hours previous and in a fasting state. Positive assays were obtained in over 80 per cent of the cases studied (Table III). These findings are in striking contrast to normal controls, where over 85 per cent of the bloods were consistently neutral. One woman showed a vasoinhibitory (eI) reaction in the blood during the menstrual period, but when tested at subsequent intervals had a neutral bioassay reaction. Evidence of vasoactivity was found in individuals with a diversity of clinical symptoms, irrespective of the presence or absence of demonstrable cardiovascular disease, or an abnormally high blood pressure. Assays on the blood of several patients suffering from the same disease (hyperthyroidism, arthritis or diabetes) showed diametrically opposed types of

2 Heparinized blood samples were obtained from the outpatient clinic of Beth Israel Hospital and tested for vasoactivity within 2 to 5 hours after being drawn. 
TABLE III

Bioassay of bloods in random sampling of clinic patients

\begin{tabular}{|c|c|c|c|c|c|c|}
\hline \multirow[b]{2}{*}{ Diagnoeis } & \multirow{2}{*}{$\begin{array}{c}\text { Age } \\
\text { (yrs.) }\end{array}$} & \multicolumn{2}{|c|}{$\begin{array}{c}\text { Blood pressure } \\
\left(\mathrm{mm} . \mathrm{Hg}_{\mathrm{g}}\right)\end{array}$} & \multicolumn{3}{|c|}{$\begin{array}{c}\text { No. of samples with specific } \\
\text { vasoactivity }\end{array}$} \\
\hline & & Systolic & Diastolic & eP & eI & Neutral \\
\hline \multirow[t]{2}{*}{$\begin{array}{l}\text { Arthritis } \\
\text { Asthma } \\
\text { A.S.H.D.* } \\
\text { Diabetes } \\
\text { G.I. disorders } \\
\text { Hypertension } \\
\text { Hyperthyroid } \\
\text { Ca breast or G.I. tract } \\
\text { Obesity } \\
\text { Rheum. heart disease } \\
\text { Assorted normotensives } \dagger\end{array}$} & $\begin{array}{l}50-73 \\
40-70 \\
60-70 \\
42-72 \\
25-50 \\
30-72 \\
30-50 \\
40-66 \\
29-59 \\
20-47 \\
27-64\end{array}$ & $\begin{array}{r}110-160 \\
110-140 \\
140-150 \\
140-170 \\
120-140 \\
165-210 \\
120-140 \\
105-120 \\
100-158 \\
90-130 \\
90-125\end{array}$ & $\begin{array}{l}80-90 \\
80-90 \\
70-80 \\
80-100 \\
70-90 \\
90-115 \\
70-80 \\
60-70 \\
70-85 \\
70-80 \\
60-85\end{array}$ & $\begin{array}{l}\frac{1}{5} \\
2 \\
5 \\
6 \\
2 \\
1 \\
1 \\
7\end{array}$ & $\begin{array}{r}3 \\
2 \\
2 \\
1 \\
4 \\
4 \\
12 \\
2 \\
5 \\
3 \\
4 \\
4 \\
5\end{array}$ & $\begin{array}{l}\frac{2}{1} \\
1 \\
3 \\
2 \\
1 \\
1 \\
1 \\
5\end{array}$ \\
\hline & \multicolumn{3}{|c|}{$\begin{array}{l}\text { Total number of patients }=90 \\
\text { Per cent in each category }=\end{array}$} & 33 & 48 & 19 \\
\hline Healthy controls & $23-42$ & $100-140$ & $70-82$ & 2 & 1 & 18 \\
\hline
\end{tabular}

* A.S.H.D. = Arterio-sclerotic heart disease.

$\dagger$ Includes patients with epilepsy, bronchitis, non-toxic goiter, polio, psychosomatic complaints, syphilis, and vasomotor rhinitis.

vasoactivity, although the clinical status of the patients appeared to be essentially the same.

The presence of vasoactive materials in the blood of patients was shown to represent a constantly shifting condition. Repeated assays on six individuals (three hypertensives, one hyperthyroid, one rheumatic heart disease, one arthritic) at intervals of from several days to several months showed fluctuating bioassay values varying between so-called "neutral," eP, and eI reactions. Here again no evident correlation was found to exist between changes in the clinical status of particular patients and the shifting vasoactivity of the blood. As can be seen in Table III, the incidence of positive $\mathrm{eP}$ and $\mathrm{eI}$ activity in the blood of hypertensives was no greater than that in several different diseases, not associated with abnormal blood pressure.

2. Shock: In the present re-evaluation of the role of VEM and VDM in the genesis of hemorrhagic shock, an attempt was made to obtain direct evidence for a humoral contribution to the vascular sequelae of shock by infusing during the two major phases of the syndrome the oppositely acting humoral component. Thus, during the initial compensatory stage, liver VDM, or ferritin was infused, while during the terminal decompensatory phase, kidney VEM was given. In these experiments, rats anesthetized with sodium pento- barbital were subjected to graded hemorrhage while connected to a bleed-out reservoir which could be elevated or lowered to maintain the blood pressure at a desired level. Infusion of vasoactive material was delivered in a volume of $0.5 \mathrm{ml}$. over a period of 60 minutes to avoid the effects of alterations in blood volume per se. Ferritin in several concentrations, .001, .01, .1, and $1.0 \mu \mathrm{g}$. per ml., was infused into four animals. Four rats were also tested with freshly prepared liver VDM and kidney VEM in full strength and at half dilution. As controls, aerobic preparations of liver and kidney incubates were infused under identical conditions into four animals. These materials did not exhibit vasoactive properties, as measured by the mesoappendix bioassay test.

It was anticipated that liver VDM or ferritin, introduced during the early phase of active compensation in shock, might counteract the characteristic patterns of vascular hyperreactivity in the mesentery. As indicated by a representative protocol in Figure 3, this did not occur. The vascular bed during this stage ( 1 hour post 2.5 per cent blood loss, blood pressure $65 \mathrm{~mm}$. $\mathrm{Hg}$ ) was highly ischemic, and hyperreactive (twenty times). No relaxation of precapillary vasoconstriction, or opening up of "inactive" capillaries was observed, despite the fact that with the infusion of $0.1 \mu \mathrm{g}$. per ml. of ferritin, blood specimens showed an eI ef- 


\section{Infusion of VDM-Compensatory Stage of Hemorrhagic Shock}

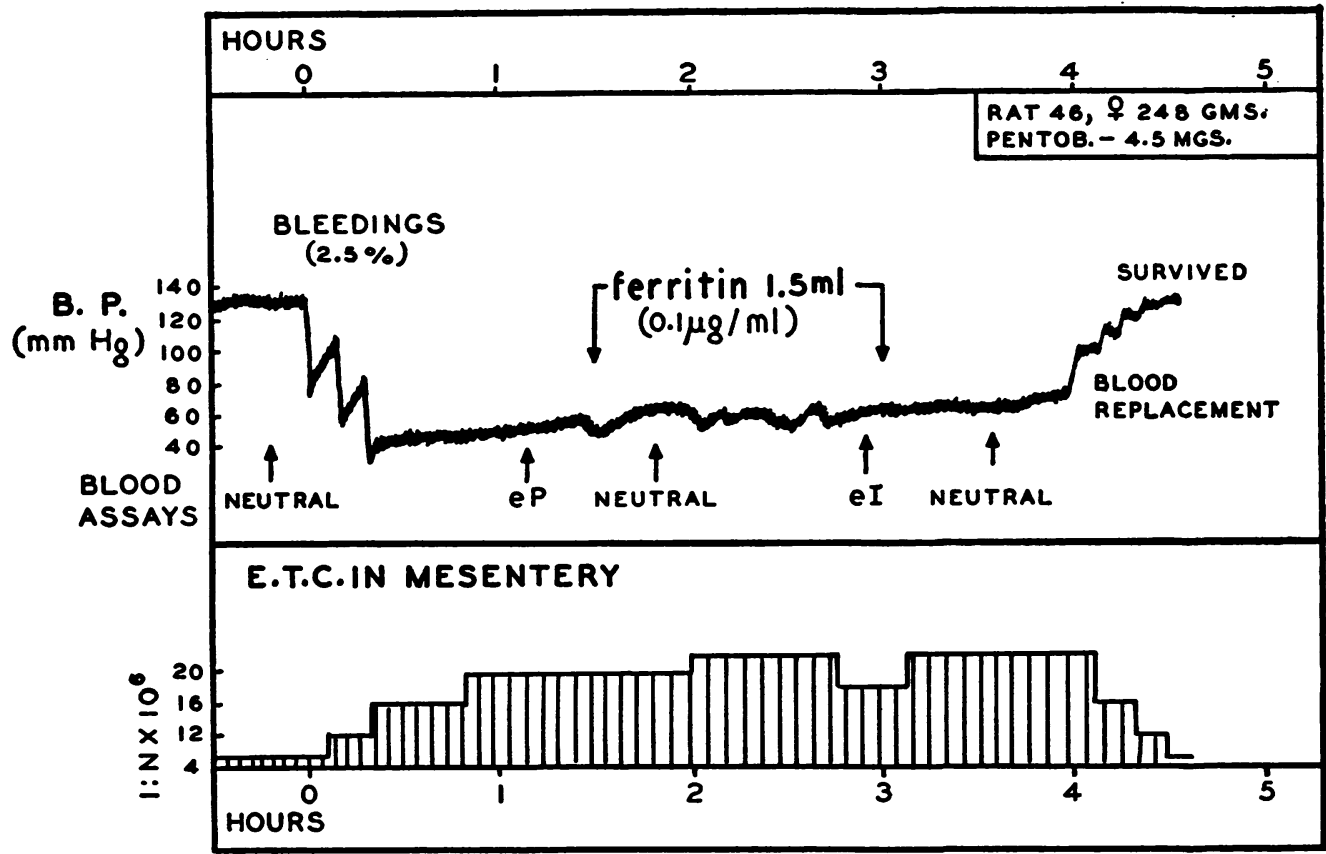

Infusion of VEM-Decompensatory Stage of Hemorrhagic Shock

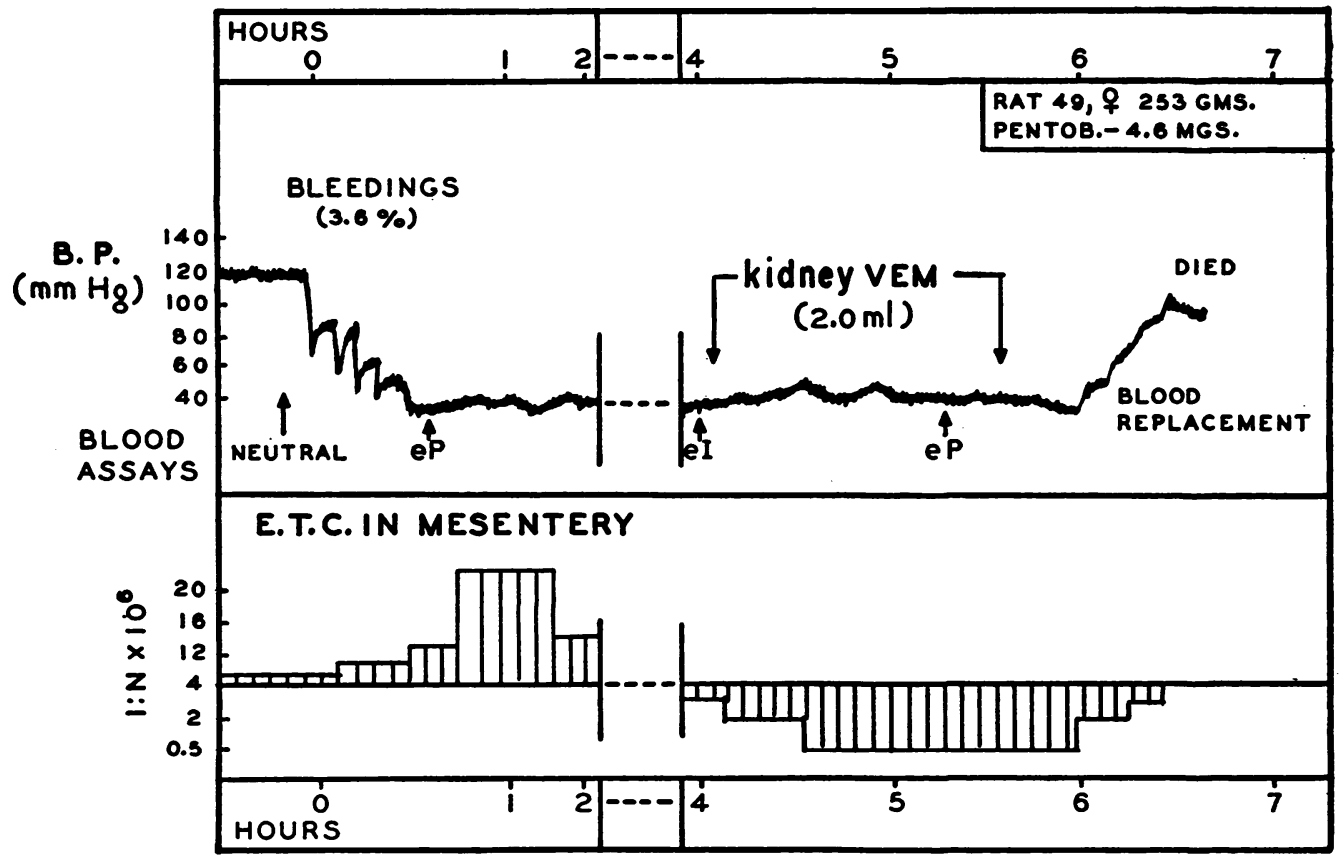

Fig. 3. (a) Intravenous Infusion of VDM during Initial Stage of Shock when the Blood Showed an eP Reaction and Mesentery a Hyperreactive Bed

Note that during infusion blood specimens elicited an eI rat test, while mesenteric vessels continued to show an eP response. No change in ready reversibility by blood replacement.

(b) Similar Experiment during State of Drastic Hypotension (2 Hrs. between 35 to 50 mM. Hg) with Kidney VEM Injected at Time when Blood Elicited an eI RAT TEST 
fect in test rats. Since vascular hyperreactivity was not abolished, this led to a situation where a preponderance of blood-borne VDM (ferritin) existed in conjunction with an eP status in the mesentery proper.

In a comparable series of experiments on six rats, the infusion of kidney VEM during the latter stage of shock ( 3 hours post 3.5 to 4.0 per cent blood loss, blood pressure $35 \mathrm{~mm}$. $\mathrm{Hg}$ ) failed to produce a salutary effect on either the sluggish blood flow in the capillary bed, or on the hyporeactive state of the metarterioles and precapillaries. A typical example of the VEM infusion studies is shown in Figure 3. Actually, the infusion of aerobic kidney incubates, which did not possess eP activity, brought about a definite improvement in capillary blood flow. The beneficial effect was transient however and the capillary flow reverted to its stagnant state almost immediately following cessation of a 60 -minute infusion.

Our earlier studies $(2,15)$ had indicated that the irreversible stage of hemorrhagic shock was associated with the appearance of VDM in the bloodstream. Exceptions to this have recently been encountered with experiments where hemorrhagic shock was induced in eviscerated animals (23). Bioassays of the blood were carried out in six such experiments. In these animals the entire intestinal tract up to the diaphragm, was surgically removed and the hepatic veins leading from the liver were then ligated. The kidneys were left in situ. This type of operative procedure was carried out with essentially no frank loss of blood, so that the blood pressure postoperatively remained within normal limits. Hemorrhagic hypotension ( $40 \mathrm{~mm}$. $\mathrm{Hg}$ after 3 per cent blood loss) resulted within 2 to $2 \frac{1}{2}$ hours in a state of shock which was completely refractory to blood replacement therapy. The blood of such animals contained no demonstrable vasodepressor material as evidenced by rat bioassay experiments.

Whether or not this type of circulatory collapse can be compared directly with that which occurs in the intact animal is, of course, open to question. However, the experiments do indicate that irreversibility can be induced in the absence of both the liver and the intestinal tract which, in the normal animal subjected to shock, appear to be the major sites of vascular decompensation and sequestration of blood from the active circulation.

3. Identification of hepatic VDM: Various independent methods have been employed with a view toward identifying the particular agent responsible for the vasoactivity of selected test samples. The premise that the eI activity of blood and tissue samples was referable to a single principle, ferritin (VDM), is based upon immunochemical inactivation of the biological effects of such samples by specific antibodies to ferritin (13). Evidence that ferritin was not the only vasoinhibitor which appeared in the blood and tissues during stress was provided by fractionation experiments

TABLE IV

Nonspecific nature of VEM and VDM

\begin{tabular}{|c|c|c|c|c|c|}
\hline \multicolumn{2}{|c|}{ Biological material } & \multirow{2}{*}{$\begin{array}{l}\text { No. of } \\
\text { rats }\end{array}$} & \multirow[b]{2}{*}{ Original activity } & \multirow{2}{*}{$\begin{array}{l}\text { Fractionation } \\
\text { procedure }\end{array}$} & \multirow[b]{2}{*}{ Final activity } \\
\hline Exptal. condition & Sample & & & & \\
\hline \multicolumn{6}{|c|}{ Vasoinhibitory } \\
\hline Hemorrhagic shock & Blood & 4 & eI, $2 x$ (32 min.) & F. antiserum ${ }^{*}$ & Neutral \\
\hline $\mathrm{X}$-radiation, $700 \mathrm{r}$ & Blood & 7 & eI, $2 x$ (48 min.) & F. antiserum & eI, $2 x$ (45 min.) \\
\hline Ischemic skeletal & Saline wash & 5 & eI, $3 x$ (37 min.) & F. antiserum & eI, $3 x$ (30 min.) \\
\hline $\begin{array}{c}\text { muscle ( } 2 \text { hrs.) } \\
\text { Tourniquet limb }\end{array}$ & Edema fluid & 6 & eI, $3 x$ (43 min.) & F. antiserum & eI, $3 x$ (40 min.) \\
\hline \multicolumn{6}{|c|}{ Vasoexcitatory } \\
\hline $\begin{array}{l}\text { L-arterenol } \\
\text { Angiotonin } \\
\text { Pitressin } 8 \\
\text { Histamine }\end{array}$ & $\begin{array}{l}2.5 \text { rg. } \\
1 \text { p.u. } \\
0.1 \text { p.u. } \\
0.2 \text { mg. }\end{array}$ & $\begin{array}{l}6 \\
4 \\
5 \\
8\end{array}$ & $\begin{array}{l}\text { eP, } 5 x(35 \text { min. } \\
\text { eP, 4x (41 min.) } \\
\text { eP, 4x (42 min.) } \\
\text { eP, 4x (38 min.) }\end{array}$ & $\begin{array}{l}\text { Kidney incub. } † \\
\text { Kidney incub. } \\
\text { Kidney incub. } \\
\text { Kidney incub. }\end{array}$ & $\begin{array}{l}\text { Neutral } \\
\text { Neutral } \\
\text { eP, } 2 x(12 \text { min. }) \\
\text { Neutral }\end{array}$ \\
\hline
\end{tabular}

* Incubation of $1.0 \mathrm{ml}$. of test sample for $30 \mathrm{~min}$. at $37.5^{\circ} \mathrm{C}$. with $0.2 \mathrm{ml}$. antisera from rabbits immunized against horse spleen ferritin.

$\dagger$ Five parts of test sample made up with Ringer-Phosphate incubated for 1 hour with one part of fresh rat kidney slices in presence of 95 per cent $\mathrm{O}_{2}, 5$ per cent $\mathrm{CO}_{2}$. 
of eI test samples obtained under the experimental conditions listed in Table IV. In contrast to the uniform inactivation of the eI activity of blood from rats in deep shock, incubation with antiserum did not destroy the biological activity of blood or tissue extracts in the situations listed.

In another series of experiments, six test rats were pretreated with antiferritin serum $(0.5 \mathrm{ml}$.) in an attempt to counteract eI effects. Although this procedure prevented the vasoinhibitory action of liver VDM or ferritin injected intravenously, eI effects equivalent to control values were still obtained with intravenous glutathione $(0.5 \mu \mathrm{g}$.) or mecholyl $(2.0 \mu \mathrm{g}$.) There was no interference with the profound eI effects initiated by the application of vasoinhibitory agents, such as acetylcholine (Mecholyl), glutathione (GSH) or cystein.

4. Identification of renal VEM: The demonstration that the eP properties of particular test samples were attributable to the renal principle, VEM, is based on inactivation by aerobic incubation with kidney tissue (2). The nonspecific nature of this procedure is shown in Table IV where aerobic incubation with rat kidney tissue destroyed not only the biological activity of renal VEM but also that of other eP substances.

\section{DISCUSSION}

The inability to provide positive evidence for a causal relationship between principles potentiating or inhibiting the response to epinephrine in the mesentery and particular aspects of circulatory regulation makes it difficult to support the systemic implications of the hepatorenal hypothesis of vascular homeostasis. The validity of the VEMVDM concept is challenged not by the failure to substantiate previously established findings in shock or hypertension, but by the demonstration that the vascular response to local epinephrine does not provide by itself a reliable measure of the general potentialities of the blood vessels to respond to stimuli or of the functional status of the vascular bed.

The hepatorenal hypothesis is predicated upon the assumption that changes visualized in the mesenteric bed were prototypes of those in other important areas. It was therefore reasonable to anticipate that the experimental introduction of VEM and VDM into the bloodstream should un- der appropriate conditions lead to some systemic manifestations. Experimental corroboration of this tenet was not provided by the current investigations. By utilizing a continuous infusion to maintain a demonstrable blood level of either kidney VEM or ferritin, it was possible to circumvent the rapid inactivation and removal of these agents from the blood stream. There was no apparent effect on either the blood pressure, or the response to pressor (epinephrine) and depressor (acetylcholine) stimuli. Comparable findings have been reported by Bohr, Paterson, Kenfield, Kitto, and Stroia (24) with acutely administered renal VEM. These experiments indicated either that these substances bore no causal relationship to blood pressure phenomena, or that their vascular influence was brought about indirectly, makingit necessary for other, as yet unknown co-factors to be present before systemic derangements were effected.

An important issue in this regard was the extent to which changes in the constrictor response of the mesenteric circulation to topical epinephrine could be construed to indicate a comparable tendency (potentiation or inhibition) in other functional reactions. Here an unpredictable situation was encountered. In terms of vascular caliber, both $\mathrm{eP}$ and eI humoral activity developed independently of a tendency towards vasoconstriction and vasodilation. Ancillary experiments showed the presence of an increased sensitivity to epinephrine in adrenalectomized rats during a period when the vessels show a loss of tone and dilate (25), and the development, with adrenergic blocking drugs, of a refractory state to epinephrine concurrent with vasoconstriction (26). These findings emphasize the uncertainty of relying upon E.T.C. alone as an index of peripheral vascular dysfunction.

The claim has been advanced that vasoexcitatory agents other than VEM exert their vascular effect on the mesenteric bed indirectly through an action on the kidney and the secondary release of VEM. In support of this thesis, Shorr and Baez (18) cited experiments in arenal animals in which they found a definite impairment of the usual epinephrine potentiation, evoked by vasoactive materials, such as 1 -arterenol and renin in normal rats. These observations were made in rats several hours after occlusion of the renal circulation by traction on exteriorized ligatures 
around the kidney pedicle. On the other hand, in our studies, acute renal occlusion had no comparable attenuating effect on the response of the terminal bed to potentiating agents. Renal occlusion, in both sets of experiments, eliminated the kidneys as a possible source of humoral material for the ensuing vascular reaction. Yet in acute situations (up to two hours in the present experiments), the injection of vasoactive agents led to a typical excitatory shift in the response to topical epinephrine. Such evidence indicated that the eP effect in these experiments could not be ascribed to the secondary release of renal VEM. A possible explanation, for the differences between acutely nephrectomized animals and those in which the kidneys were removed several hours earlier, would be the gradual loss with time of some agent, continuously secreted under aerobic conditions by the normal kidneys, necessary to sustain the capacity to respond to stimulating agents. These hypothetical agents would apparently differ from VEM which is not present in the blood under normal circumstances and has been found to be elaborated by the kidney only during stress, or under conditions of reduced circulation or hypoxia.

It has been postulated in hypertension and congestive heart failure that the chronic action of $\mathrm{eP}$ and eI principles on the terminal vascular bed disrupts local blood flow to the extent that systemic readjustments at abnormal levels become necessary to compensate for these derangements. The appearance of VEM and VDM in regular sequence during the development of renal hypertension in dogs and rats (22) represents the major support for this thesis. Since recent investigations of the biological implications of the rat bioassay method indicate that quantitative estimates of the titer of circulating material could not be achieved (19), a direct relation between these vasoactive principles and the progressive elevation of blood pressure cannot be established at present. The circumstantial nature of the evidence had made it difficult to ascertain whether the renal and hepatic principles appear during hypertension antecedent to changes in blood pressure, or whether they develop in these tissues subsequent to an increased arteriolar tone of unknown origin.

The bioassay experiments on the blood of patients with hypertension and other hospital patients must be taken into consideration in this re- gard. The demonstration of both VEM and VDM in the blood of patients suffering from a variety of diseases, irrespective of the level of their blood pressure, is not compatible with a causal relationship of these agents to abnormal blood pressure states. It would rather appear that the elaboration of $\mathrm{eI}$ and $\mathrm{eP}$ principles and their entrance into the bloodstream may represent a nonspecific sequel of an altered tissue blood flow which develops during various stress or disease conditions.

Recent investigations have suggested the existence of a variety of $\mathrm{eI}$ and $\mathrm{eP}$ substances in different experimental situations (19). It was concluded that the primary function of such humoral vasoactive agents was the intrinsic regulation of the circulation within their tissues of origin, rather than the systemic importance previously attached to such agents (2) because of their appearance in the bloodstream under different conditions. Within a considerable range, the opening and closing of precapillary sphincters and terminal arterioles constitute purely local, self-limiting phenomena concerned with the redistribution of blood in accord with tissue needs. Inasmuch as humoral vasoactive factors of the type under discussion function primarily within this sphere, it has been difficult to implicate them directly in systemic disturbances. Still problematical is the extent to which vasoactive metabolites serve a function other than that of local hormones in their particular organ of genesis.

\section{SUMMARY}

1. It has not been possible to establish a consistent relationship between the development of vasoexcitatory $(\mathrm{eP})$ or vasoinhibitory $(\mathrm{eI})$ effects in the mesentery and the degree of vasoconstriction or vasodilation which accompanies the reaction.

2. Continuous intravenous or intra-arterial infusion of kidney VEM, liver VDM or ferritin has no sustained effect on blood pressure, or the subsequent pressor response to vasoconstrictor drugs.

3. Evidence is presented to indicate that VEM and VDM probably constitute only one facet of a multiplicity of biological agents affecting the behavior of the terminal vascular bed.

4. Vasoexcitatory and vasoinhibitory agents were shown to be present in the blood of $90 \mathrm{pa}$ tients selected at random, irrespective of demon- 
strable vascular disease or the precise level of the blood pressure.

5. It is concluded that the sequential relationship of blood-borne epinephrine potentiating (eP) and inhibitory (eI) substances to particular systemic phenomena cannot be established on the basis of the evidence at present available.

\section{REFERENCES}

1. Shorr, E., Hepatorenal factors in essential hypertension in man. Hypertension: A symposium, E. T. Bell, Ed. Minneapolis, Univ. of Minnesota Press, 1951, p. 265.

2. Shorr, E., Zweifach, B. W., Furchgott, R. F., and Baez, S., Hepatorenal factors in circulatory homeostasis. IV. Tissue origins of the vasotropic principles, VEM and VDM, which appear during evolution of hemorrhagic and tourniquet shock. Circulation, 1951, 3, 42.

3. Frank, H. A., Jacob, S., Friedman, E. W., Rutenberg, A. M., Glotzer, P., and Fine, J., Traumatic shock. XXII. Irreversibility of hemorrhagic shock and VDM hypothesis. Failure of ferritin to affect arterial pressure and survival period of hepatectomized-nephrectomized dogs. Am. J. Physiol., 1952, $168,150$.

4. Hampton, J. K., Jr., Friedman, J. J., and Mayerson, H. S., An evaluation of the role of ferritin (VDM) in traumatic shock. Proc. Soc. Exper. Biol. \& Med., 1952, 79, 643.

5. Haley, T. J., and Leitch, J. L., A study of the pharmacology of ferritin. Arch. Int. Pharm. et Therap., 1954, 100, 120.

6. Bobb, J. R. R., and Green, H. D., Rôle of the kidney in resistance to ischemic compression shock. Am. J. Physiol., 1947, 150, 700.

7. Reinhard, J. J., Glasser, O., and Page, I. H., Hemorrhagic hypotension in hepatectomized and bilaterally nephrectomized hepatectomized dogs. Am. J. Physiol., 1948, 155, 106.

8. Goldblatt, H., Experimental hypertension. Fifth Conference, Factors Regulating Blood' Pressure. N. Y., Josiah Macy, Jr., Foundation, 1951, p. 100.

9. Dexter, L., Clinical criteria for the diagnosis and classification of hypertension. Fourth Conference, Factors Regulating Blood Pressure. N. Y., Josiah Macy, Jr., Foundation, 1950, p. 57.

10. Zweifach, B. W., Microscopic observations of circulation in rat mesoappendix and dog omentum: Use in study of vasotropic substances in Methods in Medical Research, V. R. Potter, Ed. Chicago, Year Book Publishers, 1948, vol. 1, p. 131.

11. Zweifach, B. W., Direct observations of the mesenteric circulation. Anat. Rec., 1954, 121, 1.

12. Zweifach, B. W., Humoral vasoactive and other metabolic derangements in shock. First Conference, Shock and Circulatory Homeostasis. N. Y., Josiah Macy, Jr., Foundation, 1951, p. 5.
13. Mazur, A., and Shorr, E., Hepatorenal factors in circulatory homeostasis. IX. The identification of the hepatic vasodepressor substance, VDM, with ferritin. J. Biol. Chem., 1948, 176, 771.

14. Page, I. H., Hypotension and loss of pressor response to angiotonin as the result of trauma to the central nervous system and severe hemorrhage. J. Exper. Med., 1943, 78, 41.

15. Zweifach, B. W., Lee, R. E., Hyman, C., and Chambers, R., Omental circulation in morphinized dogs subjected to graded hemorrhage. Ann. Surg., 1944, 120, 232.

16. Engel, F. L., Harrison, H. C., and Long, C. N. H., Biochemical studies on shock: III. The rôle of the liver and the hepatic circulation in the metabolic changes during hemorrhagic shock in the rat and the cat. J. Exper. Med., 1944, 79, 9.

17. Baez, S., Mazur, A., and Shorr, E., Hepatorenal factors in circulatory homeostasis. XX: Antidiuretic action of vasodepressor VDM (ferritin). Am. J. Physiol., 1950, 162, 198.

18. Shorr, E., and Baez, S., Differentiation of VEM from renin-hypertension on basis of action on capillary bed. Federation Proc., 1953, 12, 132.

19. Zweifach, B. W., and Metz, D. B., Biological implications of rat mesoappendix bioassay studies. Circ. Research, 1955, 3, 121.

20. Zweifach, B. W., Rosenfeld, S., Baez, S., and Shorr, $E$., The relation of the adrenal glands to the renal vasoexcitor mechanism during experimental hypertension. First Conference, Factors Regulating Blood Pressure. N. Y., Josiah Macy, Jr., Foundation, 1947, p. 72.

21. Akers, R. P., Hershey, S. G., and Zweifach, B. W., Blood-borne vasoactive substance(s) produced by splanchnic nerve stimulation. Am. J. Physiol., 1954, 178, 63.

22. Shorr, E., Comparative study of experimental renal and human essential hypertension with respect to the participation of the hepatorenal vasoactive factors, VEM and VDM. Fourth Conference, Factors Regulating Blood Pressure. N. Y., Josiah Macy, Jr., Foundation, 1950, p. 165.

23. Kelan, M., and Zweifach, B. W., Influence of partial and complete evisceration on the action of drugs protecting against lethal hemorrhage. Surg., Gynec. \& Obst., 1954, 99, 707.

24. Bohr, D. F., Paterson, R. R., Kenfield, W. J., Kitto, H. J., and Stroia, L. N., Physiological action of the renal vasoexcitor material (VEM) with reference to the pathogenesis of hypertension. Univ. of Mich. Med. Bulletin, 1952, 18, 77.

25. Zweifach, B. W., Shorr, E., and Black, M. M., The influence of the adrenal cortex on behavior of terminal vascular bed. Ann. New York Acad. Sc., 1953, 56, 626.

26. Haley, T. J., and Andem, M., The effect of topically applied adrenergic blocking agents upon the peripheral vascular sysem. J. Pharmacol. \& Exper. Therap., 1951, 102, 50. 